\title{
PREVALENCE OF COMPLAINTS AND RISK FACTORS IN PATIENTS WHO APPLIED TO THE AMBULATORY OF GENERAL PRACTICE - FAMILY MEDICINE
}

DOI: 10.36740/WLek202006133

\author{
Olexander Ye. Kononov, Liliana V. Klymenko, Olha V. Protsiuk, Oleksandr V. Klymenko, Valentyn V. Syniachenko, \\ Tetiana M. Povietkina, Vasyl T. Dobrianskyi, Nataliia F. Mykhalevych, Mariia B. Dobrianska \\ SHUPYK NATIONAL MEDICAL ACADEMY OF POSTGRADUATE EDUCATION, KYIV, UKRAINE
}

\begin{abstract}
The aim of our work was to conduct a comprehensive assessment of the frequency and features of patient's complaints, the prevalence of major vascular risk factors in patients who applied for medical care to the ambulatory of general practice - family medicine and analysis of the results based on questionnaires using the original questionnaire. Materials and methods: It was compiled a questionnaire according to which 87 people from 18 to 60 years old, were interviewed who applied to the general practice outpatient clinic - family medicine. The questionnaire included questions related to the well-being of those who went to the outpatient clinic, questions regarding the lifestyle, nutrition, bad habits, the specifics of work and the chronic pathology of the respondents and their relatives. First group included 42 (48.3\%) middle-aged patients according to WHO classification, second group - $45(51.7 \%)$ young adults.

Results: With the help of questioning of the patients who went to the outpatient clinic, we identified and statistically confirmed the risks of the occurrence and development of pathology of arterial hypertension and coronary heart disease. The odds ratio is quite high in persons with memory impairment, attention -4.41 ; feeling of heaviness in the head -3.45 ; dizziness -5.02 ; heartache -5.54 ; overweight -6.80 ; not involved in sports -3.66 in our survey groups.

Conclusions: In this study we have determined the risk groups of patients and the predictors of development of cardio- and cerebrovascular pathology in patients of the first group are revealed.
\end{abstract}

KEY WORDS: prevention, family medicine, risk groups, early diagnosis, questionnaire

Wiad Lek. 2020;73(6):1252-1256

\section{INTRODUCTION}

In the modern doctrine of health, a key role is played by prevention [1] and early diagnosis of diseases [2,3]. This is especially pronounced in primary health care. A family doctor has a great responsibility in the early diagnosis, prevention of diseases, as well as determining the patient's route $[4,5,6]$.

Cardiovascular diseases occupy a leading position in the structure of mortality not only in our country but in the whole world [7]. Therefore, the identification of early cardiovascular risk factors, their susceptibility (first line relatives) and timely evaluation of complaints that may indicate cardiovascular disease (such as arterial hypertension, diabetes mellitus, etc.) are of extreme importance to prevent conditions such as stroke, myocardial infarction and sudden cardiac death $[8,9]$. It is known that vascular risk factors such as arterial hypertension and diabetes mellitus have a long-term subclinical or asymptomatic course and should therefore be detected at the earliest possible stages to prevent damage to the target organs, namely the vessels of the brain, heart, kidneys, etc. $[9,10]$.

At the prehospital stage, almost $80 \%$ of patients begin and end treatment. Therefore, optimization of the early diagnosis of diseases is the starting point in the diagnosis, treatment, prevention of possible complications, the identification of possible risk groups with various pathologies and recovery, and, accordingly, in improving the patient's quality of life [11].

\section{THE AIM}

The aim of our work was to conduct a comprehensive assessment of the frequency and features of patient's complaints, the prevalence of major vascular risk factors in patients who applied for medical care to the ambulatory of general practice - family medicine and analysis of the results based on questionnaires using the original questionnaire.

\section{MATERIALS AND METHODS}

To achieve this goal, we compiled a questionnaire according to which 87 people were interviewed who applied to the general practice outpatient clinic - family medicine in the village of Khotov, Kiev-Svyatoshinsky district. The study included individuals from 18 to 60 years old. Patients with traumatic brain injury, infection, as well as persons in contact with radiation were excluded from the analysis.

The questionnaire included questions related to the well-being of those who went to the outpatient clinic, questions regarding 
Table I. The increase in quietness of the most important factors in the income groups.

\begin{tabular}{|c|c|c|}
\hline & Patients & Healthy \\
\hline Tinnitus & $30,77 \pm 7,39$ & $11,36 \pm 4,78$ \\
\hline Ear pain & $10,26 \pm 4,86$ & $2,27 \pm 2,25$ \\
\hline Ear plugging & $12,82 \pm 5,35$ & $18,18 \pm 5,81$ \\
\hline Memory impairment, attention* & $41,03 \pm 7,88$ & $13,64 \pm 5,17$ \\
\hline Feeling of heaviness in the head* & $56,41 \pm 7,94$ & $27,27 \pm 6,71$ \\
\hline Headache & $89,74 \pm 4,86$ & $77,27 \pm 6,32$ \\
\hline Dizziness* & $48,72 \pm 8,00$ & $15,91 \pm 5,51$ \\
\hline Pain in the heart* & $61,54 \pm 7,79$ & $25,00 \pm 6,53$ \\
\hline Reception of antihypertensive & $61,54 \pm 7,79$ & $2,27 \pm 2,25$ \\
\hline Are relatives with hypertension & $66,67 \pm 7,55$ & $54,55 \pm 7,51$ \\
\hline Relatives of patients with diabetes & $23,08 \pm 6,75$ & $31,82 \pm 7,02$ \\
\hline Overweight* & $69,23 \pm 7,39$ & $22,73 \pm 6,32$ \\
\hline Healthy eating & $61,54 \pm 7,79$ & $59,09 \pm 7,41$ \\
\hline Smoking & $12,82 \pm 5,35$ & $15,91 \pm 5,51$ \\
\hline Consuming alcohol & $46,15 \pm 7,98$ & $56,82 \pm 7,47$ \\
\hline Drinking coffee & $48,72 \pm 8,00$ & $75,00 \pm 6,53$ \\
\hline Consuming foods with high salt content & $64,10 \pm 7,68$ & $63,64 \pm 7,25$ \\
\hline Sports * & $17,95 \pm 6,15$ & $43,18 \pm 7,47$ \\
\hline Glucose levels & $87,18 \pm 5,35$ & $70,45 \pm 6,88$ \\
\hline Episodes of glucose increase & $17,65 \pm 6,54$ & $0,00 \pm 0,00$ \\
\hline Thyroid ultrasound & $51,28 \pm 8,00$ & $40,91 \pm 7,41$ \\
\hline Healthy lifestyle & $66,67 \pm 7,55$ & $77,27 \pm 6,32$ \\
\hline
\end{tabular}

* - the difference between the groups is statistically significant.

the lifestyle, nutrition, bad habits, the specifics of work and the chronic pathology of the respondents and their relatives. Tinnitus, pain and stuffiness in the ears, memory impairment, attention loss, feeling of heaviness in the head, headache, dizziness, pain in the heart, receiving antihypertensive drugs, whether there are relatives with arterial hypertension, relatives with diabetes mellitus, relatives with obesity, healthy eating, tobacco smoking, alcohol abuse, coffee overuse, consuming high-salt foods, sport activities, high glucose level, high heart rate, healthy lifestyle - a list of questions of this questionnaire. According to the study design, first group $(\mathrm{N}=42,48.3 \%)$ included middle-aged patients, while the second group $(\mathrm{N}=45,51.7 \%)$ consisted of healthy young people. There are $69(79.3 \%)$ women and 18 (20.7\%) men among them. Women in the young group were 35 (77.8\%) and middle-aged $34(81 \%)$, men $10(22.2 \%)$ and $8(19 \%)$ respectively. Statistical analysis was performed Statistical analysis was performed with Statistica 13.1. All values were expressed as means \pm standard deviation (average $\pm \mathrm{SD}$ ). Differences were considered to be significant at $\mathrm{p}<0.05$.

\section{RESULTS AND DISCUSSION}

The results of the prevalence of various factors, according to the groups, are presented in Table I.

As a result of the analysis of the factors we are studying, it should be noted: the predominance of symptoms is ill in first group. Tinnitus (30.77 $\pm 7.39 \%)$, ear pain $(10.26 \pm 4.86 \%)$, memory impairment, attention ( $41.03 \pm 7.88 \%)$, feeling of heaviness in the head $(56.41 \pm 7.94 \%)$, headache $(89.74 \pm 4.86 \%)$, dizziness $(48.72 \pm 8,00 \%)$, pain in the heart area $(61.54 \pm 7.79 \%)$ compared with the second group: tinnitus (11.36 $\pm 4.78 \%)$, ear pain $(2.27 \pm 2.25 \%)$, memory impairment, attention (13.64 \pm $5.17 \%)$, feeling heaviness in the head $(27.27 \pm 6.71 \%)$, headache $(77.27 \pm 6.32 \%)$, dizziness ( $15.91 \pm 5.51 \%)$, pain in the heart area $(25.00 \pm 6.53 \%)$. As for bad habits, smoking, alcohol and coffee were more frequently reported by the second group, $(15.91 \pm 5.51 \%),(56.82 \pm 7.47 \%)$, and $(75.00 \pm 6.53 \%)$, and in the first group $(12.82 \pm 5.35 \%),(46.15 \pm 7.98 \%),(48.72 \pm 8.00 \%)$ respectively. Healthy eating is not much more commonly adhered to by representatives of group 1 (61.54 $\pm 7.79 \%)$, against $(59.09 \pm 7.41 \%)$ of the second group, while the consumption of products with high salt content was approximately the same in both groups ( $64.10 \pm 7.68 \%)$ and $(63.64 \pm 7.25 \%)$. The intake of antihypertensive drugs was predominant in the subjects of the first group $(61.54 \pm 7.79 \%)$ compared with the second group $(2.27 \pm 2.25 \%)$. Tendency to overweight was noted in the first group $(69.23+7.39 \%)$ relative to the second group $(22.73+$ $6.32 \%)$. Also, there was a history of arterial hypertension and diabetes mellitus in relatives (66.67 $\pm 7.55 \%),(23.08 \pm 6.75 \%)$ in the first group and $(54.55 \pm 7.51 \%),(31.82 \pm 7.02 \%)$ in the second group, respectively. But sports, a healthy lifestyle was more frequently observed in the second group $(43.18 \pm 7.47 \%)$ 

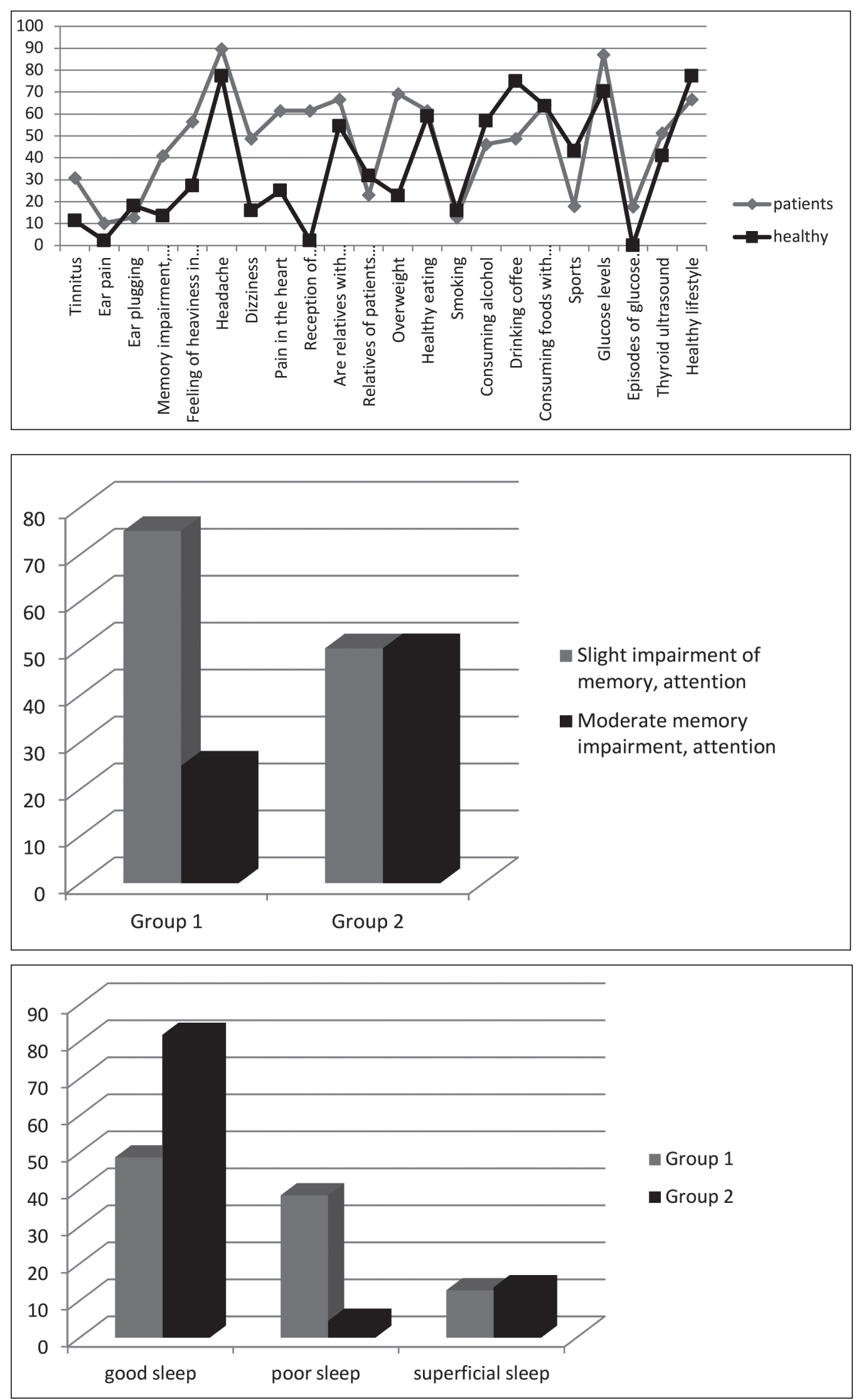

Fig. 1. The distribution of the studied factors in groups, $\%$.
Fig. 2. The quality of sleep according to the patient, $\%$.
Fig. 3. Damaged memory, respect, $\%$. and $(77.27 \pm 6.32 \%)$ as opposed to $(17.95 \pm 6.15 \%)$ and $(66.67 \pm$ $7.55 \%)$ of the first group. Determination of blood glucose level and thyroid ultrasound were performed more often by representatives of group $1,(87.18 \pm 5.35 \%)(51.28 \pm 8.00 \%)$, against
$(70.45 \pm 6.88 \%)$ and $(40.91 \pm 7.41 \%)$ of the examined group 2. In this case, episodes of glucose increase were observed exclusively in the examined the first group $(17.65 \pm 6.54 \%)$. These research factors are shown in Figure 1. 


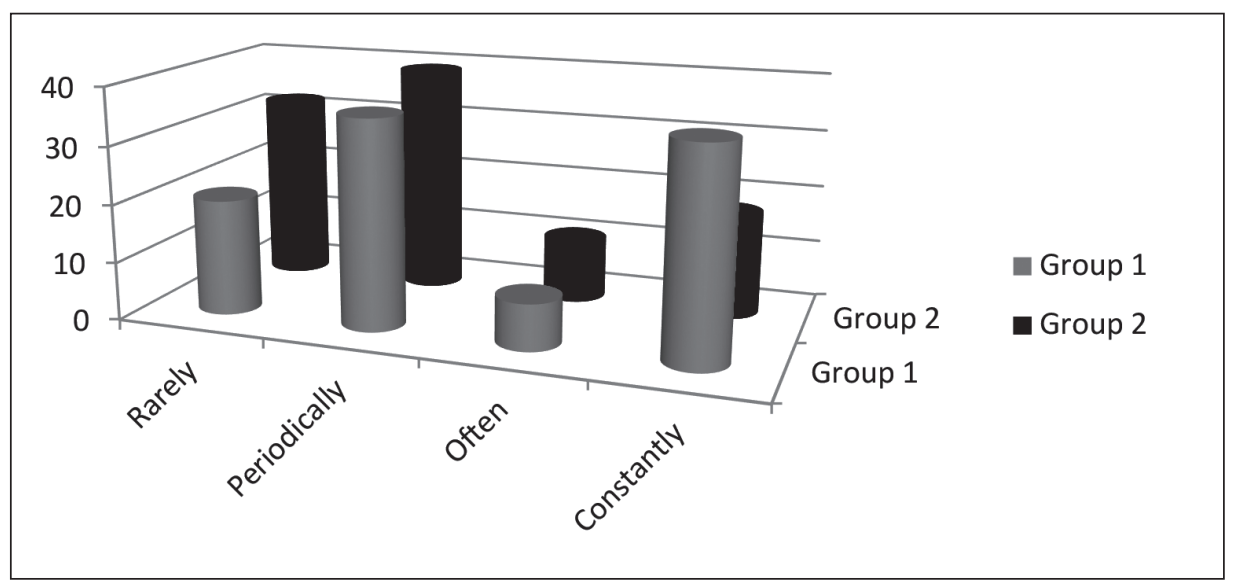

Fig. 4. Consumption of products with high salt content, $\%$.
Table II. Prevalence of various factors in study groups among those who believe they are leading a healthy lifestyle, \%.

\begin{tabular}{ccc}
\hline & Group 1 & Group 2 \\
\hline Healthy eating & $61,54 \pm 7,79$ & $59,09 \pm 7,41$ \\
\hline Smoking & $11,54 \pm 6,27$ & $14,71 \pm 6,07$ \\
\hline Alcohol use & $42,31 \pm 9,69$ & $55,88 \pm 8,52$ \\
\hline Drinking coffee & $46,15 \pm 9,78$ & $70,59 \pm 7,81$ \\
\hline Eating high-salt foods & $53,85 \pm 9,78$ & $52,94 \pm 8,56$ \\
\hline Sport activities & $23,08 \pm 8,26$ & $55,88 \pm 8,52$ \\
\hline
\end{tabular}

Also, we conducted an analysis of the quality of sleep of the subjects in both groups. Good sleep was observed among the subjects in the second group $(81.82+\%)$ versus $(48.72+\%)$ in the first group, respectively. Poor sleep was noted by $38.46+7.79 \%$ of the examined the first group and $4.55+3.14 \%$ from the second group. Moreover, superficial sleep was almost evenly observed, as in group $1(12.82+5.35 \%)$. and in group $2(13.64+5.17 \%)$. Figure 2 shows the relationship between sleep quality in groups.

As for impaired memory and attention, patients in the first group noted minor $(75.00+10.83 \%)$ and $(25.00+10.83 \%)$ mild impairments, and in the second group these changes were equally distributed as shown in Figure 3.

The constant use of foods with a high salt content of more than 2 times is observed in the first group. $(36.00+9.60 \%)$ in relation to $(17.86+7.24 \%)$ in the second group, respectively. Frequent and periodic use of such products slightly prevailed in group $2(10.71+5.85 \%),(39.29+9.23 \%)$, versus $(8.00+5.43 \%)$, $(36.00+9.60 \%)$ of group 1. Rarely consumed foods with a high salt content were representatives of the second group (32.14 + $8.83 \%)$ compared with the first group $(20.00+8.00 \%)$. This ratio is shown in details in Figure 4.

In the analysis of the factors of proper nutrition, bad habits, overuse of a number of products and prevention of hypodynamia in both groups, among those who believe that they lead a healthy

Table III. The risk of pathology (AH and CHD) in the presence of factors.

\begin{tabular}{|c|c|c|c|c|}
\hline & Odds ratio & Confidence interval & Xi-square & $\mathbf{p}$ \\
\hline Tinnitus & 3,47 & $0,98-12,93$ & 3,66 & 0,056 \\
\hline Ear pain & 4,91 & $0,48-120,96$ & 1,13 & 0,287 \\
\hline Congestion in the ears & 0,66 & $0,17-2,54$ & 0,14 & 0,713 \\
\hline Memory impairment, attention & 4,41 & $1,36-14,87$ & 6,62 & 0,01 \\
\hline Feeling of heaviness in the head & 3,45 & $1,26-9,63$ & 6,10 & 0,013 \\
\hline Headache & 2,57 & $0,65-10,91$ & 1,19 & 0,222 \\
\hline Dizziness & 5,02 & $1,63-15,98$ & 8,88 & 0,003 \\
\hline Heartache & 5,54 & $1,92-16,36$ & 11,44 & $<0,001$ \\
\hline Are relatives with hypertension & 1,67 & $0,62-4,49$ & 0,81 & 0,367 \\
\hline Relatives of patients with diabetes & 0,67 & $0,22-1,97$ & 0,33 & 0,568 \\
\hline Overweight & 6,80 & $2,28-20,87$ & 13,90 & $<0,001$ \\
\hline eating healthy & 1,11 & $0,42-2,94$ & 0,00 & 0,998 \\
\hline Smoking & 0,76 & $0,19-3,01$ & 0,02 & 0,897 \\
\hline Consuming alcohol & 0,65 & $0,25-1,69$ & 0,56 & 0,453 \\
\hline Drinking coffee & 0,32 & $0,11-0,88$ & 5,03 & 0,024 \\
\hline Eating high-salt foods & 0,96 & $0,35-2,61$ & 0,02 & 0,892 \\
\hline Not engaged in sports & 3,66 & $1,19-11,59$ & 15,37 & 0,02 \\
\hline
\end{tabular}


lifestyle, it was found that in the second group, the examinees use alcohol and coffee much more often: $(55.88+8.52 \%)$ and (70.59 $+7.81 \%)$ in the second group and $(42.31+9.69 \%)$ and $(46.15+$ $9.78 \%$ ) in the first group, respectively. The percentage of smokers in the second group $(14.71+6.07 \%)$ was relatively insignificant compared to the first group $(11.54+6.27 \%)$. Products with a high salt content were used by representatives of both groups approximately equally $(53.85+9.78 \%)$ in the first group and $(52.94+8.56 \%)$ in the second group. However, persons in the first group were significantly less likely to play sports $(23,08+$ $8.26 \%)$ compared to the second group $(55.88+8.52 \%)$. The data are presented in Table II.

At the same time, among the smokers who do not want to stop it, one third in the group with pathology and five in the group of healthy persons.

With the help of questioning of the patients who went to the outpatient clinic, we identified and statistically confirmed the risks of the occurrence and development of pathology of arterial hypertension and coronary heart disease. The odds ratio is quite high in persons with memory impairment, attention - 4.41; feeling of heaviness in the head - 3.45; dizziness - 5.02; heartache - 5.54; overweight - 6.80; not involved in sports - 3.66 in our survey groups. Details of the risk of pathology are presented in Table III.

Thanks to monitoring and systematization of complaints of patients who applied for medical care to the outpatient clinic of general practice - family medicine, we identified negative factors affecting the health of those who addressed and identified "risk" groups among them. Conducting such an analysis in outpatient clinics of general practice - family medicine can help identify trends in morbidity in the regions and, accordingly, their early diagnosis and prevention.

\section{CONCLUSIONS}

1. The study revealed changes that show signs of cerebro-asthenic syndrome, noted the negative impact of diet and a tendency to hypodynamics, which were characteristic of persons of the first group.

2. It is established that disorders of memory, attention, heaviness in the head, dizziness, pain in the heart, predisposition to overweight are predictors of cardiovascular and cerebrovascular pathology.

\section{REFERENCES}

1. KilıçS., Saraçoğlu E., Çekici Y. et al. Comparison of secondary prevention in coronary heart disease patients living in rural and urban areas. Turk Kardiyol Dern Ars. 2019; 47(2): 128-136.

2. Silina V., Kalda R. Challenges for clinical practice and research in family medicine in reducing the risk of chronic diseases. Notes on the EGPRN Spring Conference 2017 in Riga. Eur J Gen Pract. 2018; 24(1): 112-117.

3. Csige I., Ujvárosy D., Szabó Z. et al. The impact of obesity on the cardiovascular system. J Diabetes Res. 2018; 2: 125-134.

4. ParkashJ.,KalhanM.,Singhania K. etal. Dissemination of Arterial Hypertension and its Determinants among Police Officers in Haryana, India. International Journal of Applied and Basic Medical Research. 2019; V. 9: 143-147.

5. Kim X., Kim C., Yong C. et al. Prevalence and incidence of atherosclerotic cardiovascular disease and its risk factors in Korea: a nationwide population-based study. BMC Public Health. 2019; 19(1): 1112.
6. Gupta P., Khedar RS., Gaur K. et al. Low quality cardiovascular care is an important coronary risk factor in India. Indian Heart J. 2018; 70. Suppl 3: 419-430.

7. Filipets 0.0. , Pashkovsky V. M. Naslidki insultu v Ukraini: analiz oficijnoji statistiki insutu ta oglad na osnovi epidemiologichnih doslidzhen [Stroke Burden in Ukraine: Analysis of the Official Stroke Statistics and Overview of Population-Based Epidemiological Studies]. J Clin Exp Pathol. 2014; 13 (3): 189-193. (Ua)

8. Piepoli M. F., Hoes A. W., Albus C. et al. European Guidelines on cardiovascular disease prevention in clinical practice. Eur. Heart J. 2016; 37:2315-81.

9. Nelson M. R. Doust J. A. Primary prevention of cardiovascular disease: new guidelines, technologies and therapies. Med. J. 2013; 198 (11): 606-10.

10. Trishchynska M. A. Potokozalezhna vazodilyatatsiya u zhinok z pochatkovimi proyavami hronichnoyi ishemiyi mozku [Flowmediated dilation in women with initial manifestations of cerebral ischemia]. Zdorovoje zhenschinyi. 2016; 2 (108): 56-59. (Ua)

11. Trishchynska M. A. Stan sudinoruhovoyi funktsiyi endoteliyu v patcientiv ztserebrovaskulyarnoyu patologieyu riznogo stupenya tyazhkosti [State of vasomotor endothelial function in patients with cerebrovascular pathology different severity]. Ukrayinskiy nevrologlchniy zhurnal. 2015; 3: 26-29. (Ua)

The article is a fragment of the scientific research work "Scientific substantiation of modern approaches to optimization of preventive directions at the primary level of providing medical care" (deadline - 2018-2022, state registration number 0113U002455).

\section{ORCID and contributionship:}

Olexander Ye. Kononov - 0000-0003-0505-0296 A,D

Liliana V. Klymenko - 0000-0001-6749-113X ${ }^{E, F}$

Olha V. Protsiuk - 0000-0002-5038-3375 ${ }^{\mathrm{C}}$

Oleksandr V. Klymenko - 0000-0001-8261-2542 ${ }^{F}$

Tetiana M. Povietkina - 0000-0002-9442-2188 ${ }^{E}$

Valentyn V. Syniachenko - 0000-0001-5555-0577 ${ }^{E}$

Vasyl T. Dobrianskyi - 0000-0001-7573-8008 ${ }^{B}$

Nataliia F. Mykhalevych - 0000-0002-8925-962X ${ }^{B}$

Mariia B. Dobrianska - 0000-0002-6550-1442 ${ }^{B}$

\section{Conflict of interest:}

The Authors declare no conflict of interest.

\section{CORRESPONDING AUTHOR}

Liliana V. Klymenko

Shupyk National Medical Academy of Postgraduate Education

9 Dorohozhytska str., 04112 Kyiv, Ukraine

tel: +380442881034

e-mail:dr-liliana-ua@ukr.net

Received: 25.01 .2020

Accepted: 07.05 .2020 